\title{
Opportunities and Barriers for Family Physician Contribution to the Maternity Care Workforce
}

Tyler W. Barreto, MD; Aimee R. Eden, PhD, MPH; Elizabeth Rose Hansen, BA; Lars E. Peterson, MD, PhD

\begin{abstract}
BACKGROUND AND OBJECTIVES: The number of family physicians providing obstetric deliveries is decreasing, but high numbers of new graduates report they intend to include obstetric deliveries in their practices. The objective of this study was to understand barriers to providing obstetrical care faced by recent family medicine residency graduates who intended to provide obstetrical care at graduation.
\end{abstract}

METHODS: Email surveys were sent to graduating family medicine residents who indicated intention to include obstetrics in their practice on the American Board of Family Medicine (ABFM) Certification Examination Registration Survey (2014-2016). We used descriptive and bivariate statistics to analyze the data.

RESULTS: Of our sample of 2,098 early career family physicians, 1,016 (48.4\%) responded. Seven hundred (68.9\%) currently include obstetrics in their practices. Those currently including obstetrics were more likely to practice in a small rural or isolated $(15.4 \%$ vs $5.2 \%$ and $4.6 \%$ vs $1.7 \%, P<0.001)$ community and report credentialing was easy $(85.2 \%$ and $26.5 \%$, respectively, $P<0.001)$. Physicians not currently including obstetrics in their practice reported "found a job without OB" and "lifestyle concerns" as the most significant barriers. Respondents living in the Middle Atlantic and West South Central regions were least likely to provide obstetric deliveries, with fewer than $50 \%$ doing so.

CONCLUSIONS: Among recent graduates who intended to practice obstetrics, finding a job without obstetrics and lifestyle concerns were the most significant barriers to realizing the scope of practice they intended.

(Fam Med. 2019;51(X):pp-p.)

doi: 10.22454/FamMed.2019.845581

Published Online First March 13, 2019

$\mathbf{T}$ he narrowing scope of practice for family physicians is well documented. Fewer family physicians are providing prenatal care, inpatient care, pediatric care, and obstetric care. ${ }^{1-4}$ Concurrently, the value of a broad scope of practice, or more comprehensiveness in family medicine, has been quantified with evidence showing lower costs and lower hospitalization rates when family physicians practice broadly. ${ }^{5}$ Despite evidence that a broad scope is valuable and family medicine residency curricula to train physicians to provide a broad scope of practice, many are not practicing a broad scope after graduation. ${ }^{6}$

Of particular concern is the continued steep decline in the number of family physicians practicing obstetric care, which greatly impacts both comprehensiveness in family medicine and the obstetric workforce. ${ }^{7}$ The American College of Obstetricians and Gynecologists has projected a growing shortage in the obstetric workforce, and approximately half of all counties in the United States do not currently have an obstetrician-gynecologist. ${ }^{8}$ Only $8 \%$ of family physicians currently include obstetric deliveries in their practice. ${ }^{7}$ A declining obstetric workforce and maldistribution of obstetric providers is particularly concerning in rural areas where family physicians provide the majority of maternity care and where labor and delivery units are closing., 90

Having traditionally contributed to the obstetric workforce, family physicians could play a critical role in solving the obstetric shortage. Current estimates have found $8 \%$ of family physicians include obstetrics in their practice, but new family physicians want to practice obstetrics at much higher rates., ${ }^{4,7}$ In a 3 -year cohort (2014-2016), 23\% of family medicine graduates reported intention to include obstetric deliveries in their practice. This translates

From the University of Texas Health Science Center at San Antonio Department of Family and Community Medicine (Dr Barreto), and the American Board of Family Medicine, Lexington, KY (Drs Eden and Peterson, and Ms Hansen). 
to more than 2,000 family physicians who graduated between 2014 and 2016 and intended to include obstetrics in their practice who could be mitigating the obstetric workforce problems. ${ }^{4}$

If there are 2,000 graduating family physicians who intend to include obstetric deliveries in every 3-year cohort, ensuring that they are able to practice their intended scope could be part of the solution to shortage and decreased access to obstetric care in the United States. If these new physicians are not currently including obstetric deliveries, it is important to identify modifiable barriers. Studies from the 1990s showed malpractice insurance and lifestyle concerns as major barriers, but to inform policy today, we need to identify and understand barriers FPs face currently. ${ }^{11,12}$ In this study, we aimed to characterize the obstetric practice patterns and barriers faced by those 2,000 recent family medicine graduates who intended to include obstetric deliveries in their practice.

\section{Methods}

We identified all family physicians who answered "yes" to the obstetrical deliveries option on the question "I plan on providing the following care in my practice after graduation" on the American Board of Family Medicine (ABFM) Certification Examination Registration Questionnaire from 2014 through 2016 and had a valid email address in the ABFM administrative databases (Figure 1). We distributed a five-question survey via SurveyMonkey to 2,098 family physicians. Invitations to participate were sent weekly for 3 weeks. There was no incentive given to participate in this survey. The survey questions addressed: (1) how committed they were to including obstetrics in their practice at the time of their graduation; (2) if they were currently practicing obstetric deliveries; (3) if delivering, how many per year, or if not delivering, why not (in ranked order); (4) the ease of credentialing (on a Likert scale); and (5) whether
Figure 1: Family Physicians Included in the Survey

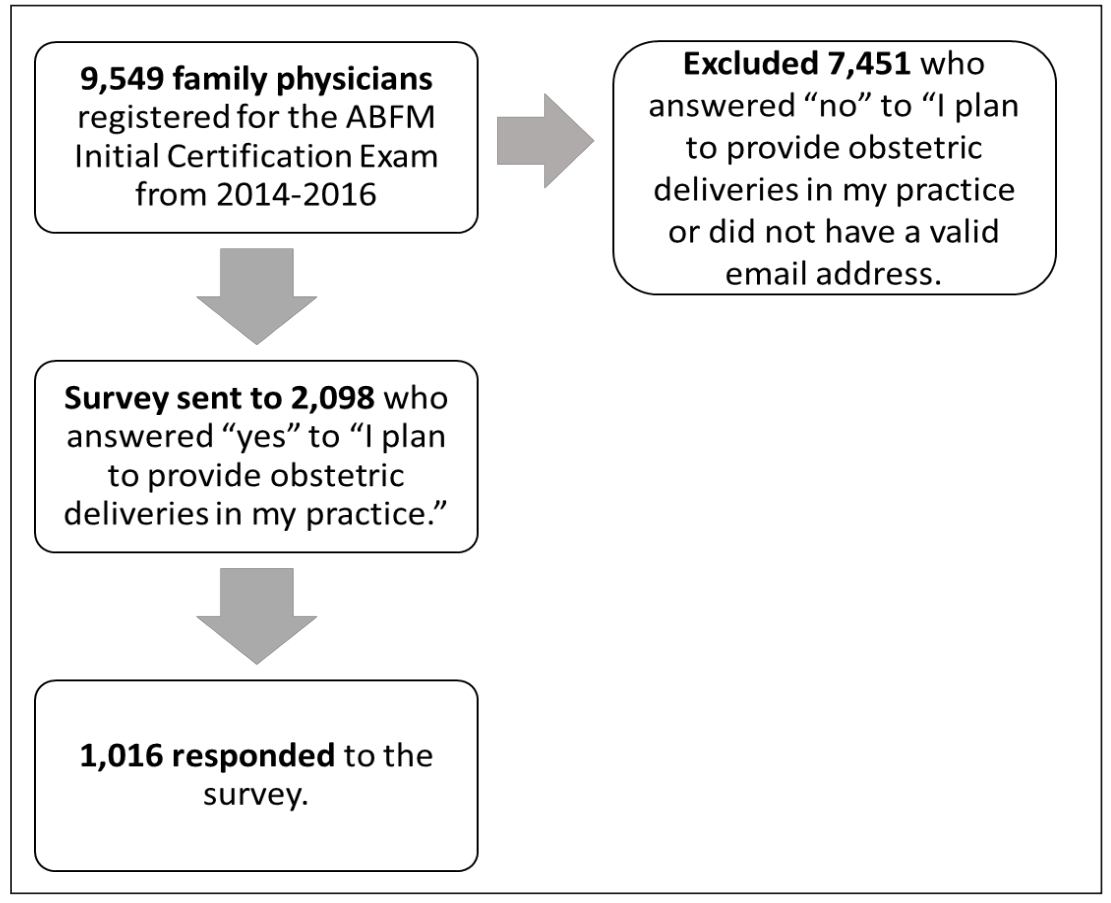

they would be willing to participate in an interview.

Demographic data was obtained from ABFM administrative databases. Rurality was based on RuralUrban Commuting Area (RUCA) as defined by zip codes. ${ }^{13}$ Data from zip codes that did not exist in the latest update of RUCA in 2006 and from physicians practicing outside of the United States were excluded from the analysis of rurality. We investigated regional differences based on state of current practice from ABFM data and categorized using Census Divisions. ${ }^{14}$

All nominal data were analyzed using Pearson $\chi^{2}$, and ordinal data were analyzed using Wilcoxon-MannWhitney tests. The Likert scale was treated as an ordinal variable. The AAFP Institutional Review Board approved this study.

\section{Results}

Of the 2,098 invitations sent, 1,016 (48.4\%) physicians responded to the survey. Of these, $700(68.9 \%)$ reported currently including obstetric deliveries in their practice (Table 1). There was no difference in gender $(66.9 \%$ and $60.7 \%$ female respectively, $P=0.059$ ) or type of medical degree $(83.1 \%$ and $84.2 \%$ allopathic respectively, $P=0.681$ ) between those delivering and those not. Physicians currently including obstetric deliveries were slightly younger (33.2 years vs 34.5 years, $P<0.001$ ) and more likely to be at small rural or isolated ( $15.4 \%$ vs $5.2 \%$ and $4.6 \%$ vs $1.7 \%, P<0.001)$ communities. There was a difference in current inclusion of obstetric deliveries based on Census Division $(P<0.001)$. Most significantly, less than $50 \%$ of respondents were delivering babies in the Middle Atlantic and West South Central divisions, while 75\% or more were delivering in the East North Central, West North Central, and Mountain divisions.

Those currently including obstetrics were more likely to report being committed to doing so, marking "highly committed," "mostly committed," and "committed" (97.3\%), than those who were not $(67.4 \%, P<0.001)$. Respondents who answered "yes" to including obstetric deliveries were more likely to report the credentialing process as "easy" or "very easy" compared to those not including obstetric deliveries $(85.2 \%$ and $26.5 \%$ 
Table 1: Characteristics of New Family Physicians Planning to Include Obstetric Deliveries in Their Practice After Graduation

\begin{tabular}{|c|c|c|c|}
\hline & Currently Delivering & Not Currently Delivering & $P$ Value \\
\hline $\mathrm{n}(\%)$ & $700(68.9)$ & $316(31.1)$ & \\
\hline Female $(\%)$ & $468(66.9)$ & $192(60.7)$ & 0.059 \\
\hline $\mathrm{MD}(\%)$ & $582(83.1)$ & $266(84.2)$ & 0.681 \\
\hline Age $(\%)$ & 33.2 & 34.5 & 0.001 \\
\hline Rurality $(\%)^{*}$ & & & $<0.001$ \\
\hline Urban & $484(71.1)$ & $244(83.9)$ & \\
\hline Large rural & $61(9.0)$ & $27(9.3)$ & \\
\hline Small rural & $105(15.4)$ & $15(5.2)$ & \\
\hline Isolated & $31(4.6)$ & $5(1.7)$ & \\
\hline Region $(\%)^{* *}$ & & & $<0.001$ \\
\hline New England (CT, ME, MA, NH, RI, VT) & $33(71.7)$ & $13(28.3)$ & \\
\hline Middle Atlantic (NJ, NY, PA) & $30(48.4)$ & $32(51.6)$ & \\
\hline East North Central (IL, IN, MI, OH, WI) & $109(76.2)$ & $34(23.8)$ & \\
\hline West North Central (IA, KS, MN, MO, NE, ND, SD) & $138(82.6)$ & $29(17.4)$ & \\
\hline South Atlantic (DE, DC, FL GA, MD, NC, SC, VA, WV) & $50(62.5)$ & $30(37.5)$ & \\
\hline East South Central (AL, KY, MS, TN) & $23(63.9)$ & $13(36.1)$ & \\
\hline West South Central (AR, LA, OK, TX) & $34(44.7)$ & $42(55.3)$ & \\
\hline Mountain (AZ, CO, ID, MT, NV, NM, UT, WY) & $109(74.7)$ & $37(25.3)$ & \\
\hline Pacific (AK, CA, HI, OR, WA) & $159(71.0)$ & $65(29.0)$ & \\
\hline Other $\dagger$ & $14(38.9)$ & $22(61.1)$ & \\
\hline
\end{tabular}

*Rurality is based on rural-urban commuting area (RUCA) as defined by zip codes. Missing data were from zip codes that did not exist in the latest update in 2006.

**Region is based on state of current practice from ABFM data and categorized using census divisions.

$\dagger$ "Other" includes overseas military addresses for armed forces in Europe, the Middle East, Africa, and Canada; overseas military addresses for the Pacific, Guam, and Canada.

respectively, $P<0.001$, Figure 2). Most respondents $(75 \%)$ who included obstetrics reported performing 40 or fewer deliveries per year (Figure 3). Of those not currently including obstetric deliveries (Figure 4), "found a job without OB" was the most common reason to be ranked first $(26.2 \%)$, followed by "lifestyle concerns" (18.7\%). Only $10.9 \%$ ranked "malpractice" as their top reason. "Lifestyle concerns" was most commonly ranked in the top three reasons $(52.1 \%)$, closely followed by "found a job without OB" (48.3\%), then "malpractice" (35.2\%).

\section{Discussion}

We found the most significant reason that family physicians did not include obstetric deliveries as intended was that they found a job without $\mathrm{OB}$. This concerning finding may be related to the increasing rate of physician employment. ${ }^{15}$ Perhaps as new physicians enter the employed model, becoming employees rather than owners, job offerings and constraints may be a driving force in limiting the scope of family medicine. If family physicians' scope of practice today is dictated by health care systems and not by family physicians, policy intending to increase scope, and therefore access to care, should be directed at the employers.

Malpractice was not identified as a top barrier, though 35\% did rank it in their top three reasons for not providing obstetrical care. This is consistent with previous research showing malpractice burden alone did not lead family physicians to stop providing obstetric care. ${ }^{16} \mathrm{~A}$ study in Oregon found that subsidizing malpractice premiums did not increase the rates of family physicians providing obstetric care. ${ }^{17}$ However, older research identified malpractice as a commonly cited reason for not including obstetrics. ${ }^{17,18}$ The reduced influence of malpractice on 
Figure 2: Ease of Credentialing

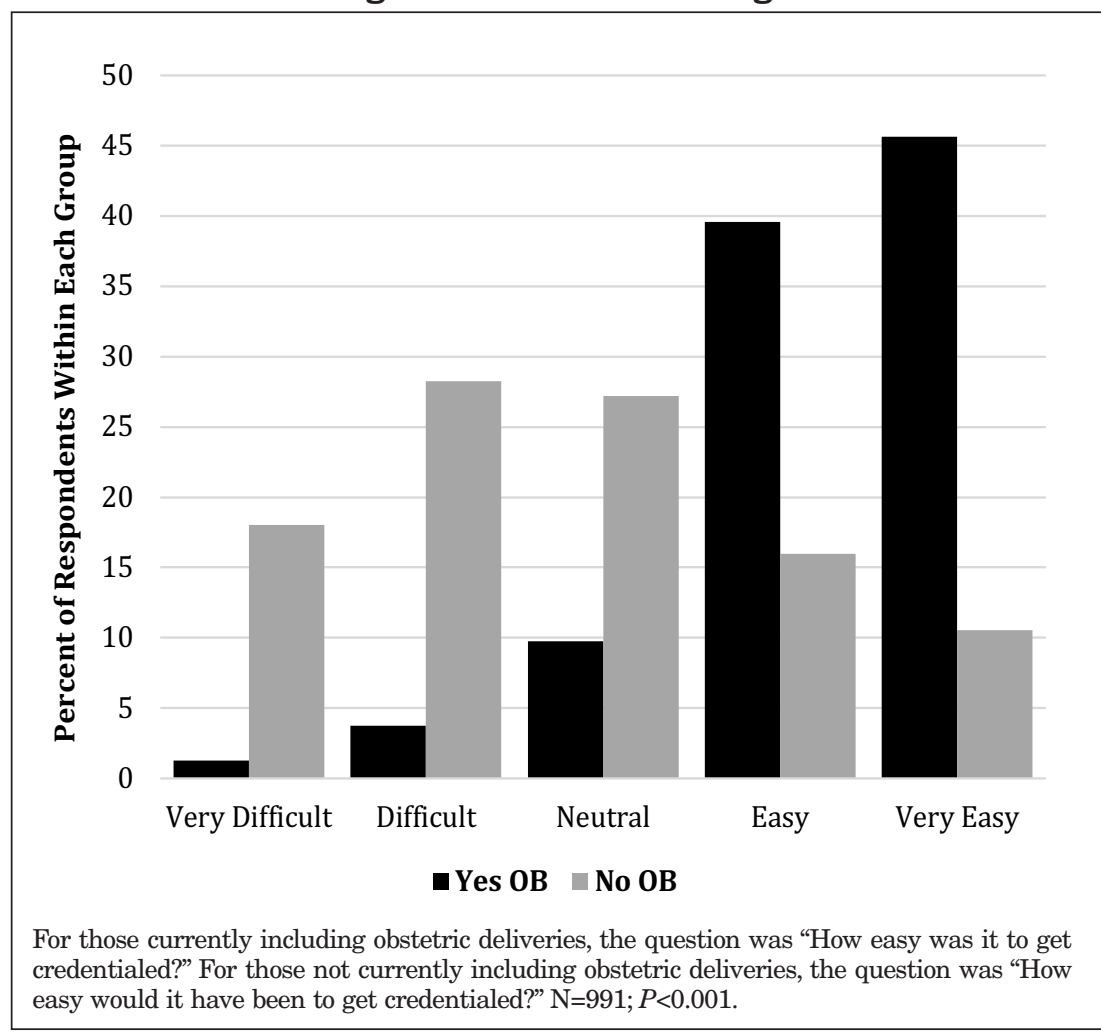

Figure 3: Number of Deliveries Performed Annually by Those Who Are Including Obstetric Deliveries $(\mathrm{N}=700)$

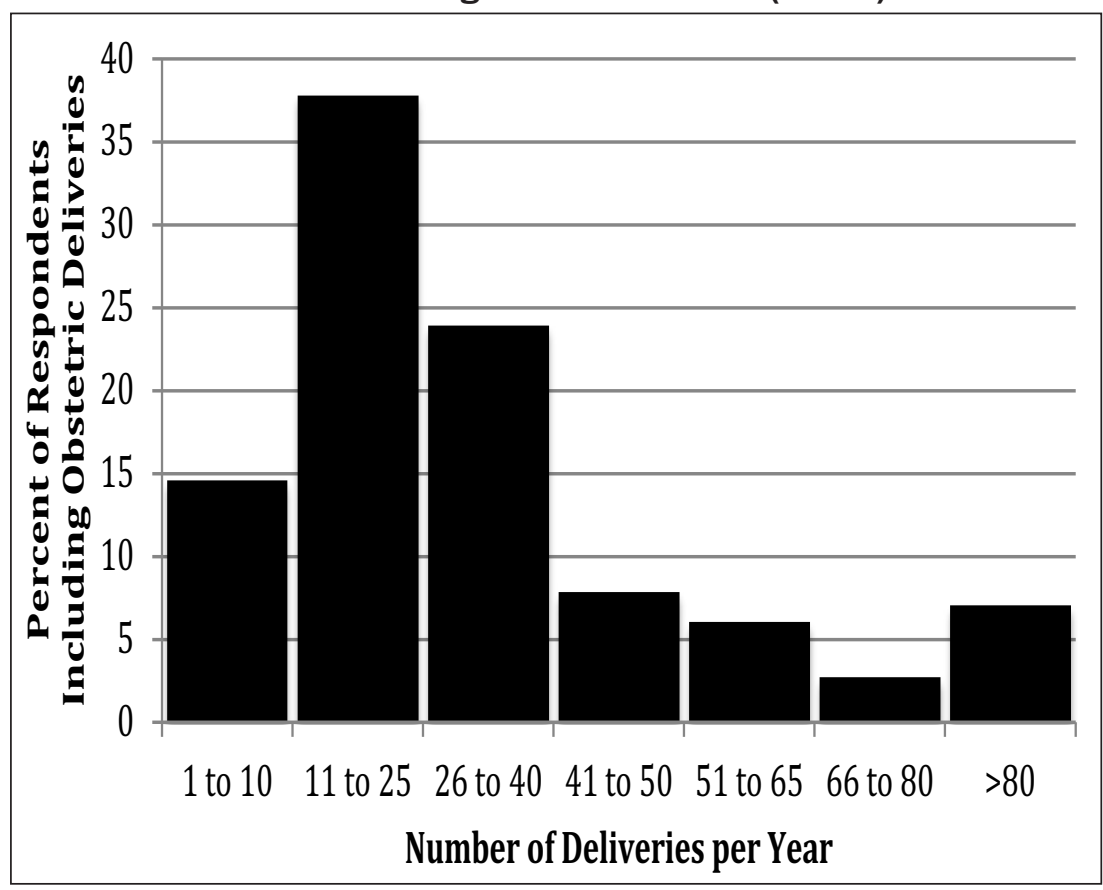

the inclusion obstetrics found in this study may be due to increasing physician employment, as employers, not physicians themselves, bear responsibility for malpractice coverage.

While credentialing was not identified as a significant barrier, we found a significant difference in ease of getting credentialed between those who were currently including obstetrics and those who were not. Credentialing, malpractice, and inability to find a job are all barriers that may be affected by the increasing rates of physician employment. ${ }^{15}$ The impact of employment should be examined in future studies to help inform policy to increase access to maternity care.

The other most frequently selected barrier was lifestyle concerns, reflecting findings from earlier research. ${ }^{19}$ This is an interesting concern among these survey respondents who all reported intention to practice obstetrics. Perhaps the impact of obstetrics on lifestyle, as expected based on training experience, is different outside of the residency setting. If the lifestyle barrier is related to expectations, then implementing role modelling or practice mentoring may be helpful. Lifestyle concerns could also be a consequence of fewer family physicians including obstetrics in their practice, leaving those who are providing obstetric care with more patients and a heavier call burden. If other barriers are addressed and more family physicians include obstetrics in their practice, this could lighten the call burden for all.

Only $11.6 \%$ of respondents reported training as the top barrier to including obstetric deliveries in their practice. Previous studies have shown a continued broad scope education in residencies overall and that programs with stronger obstetric training produce more physicians providing obstetric care, indicating that intensity of training is important, but not the primary driver for narrowing scope in practice. ${ }^{6,20,21}$

Geographical location was related to a new physician's success in including obstetric deliveries in 
Figure 4: Barriers to Including Obstetric Deliveries in Their Practice

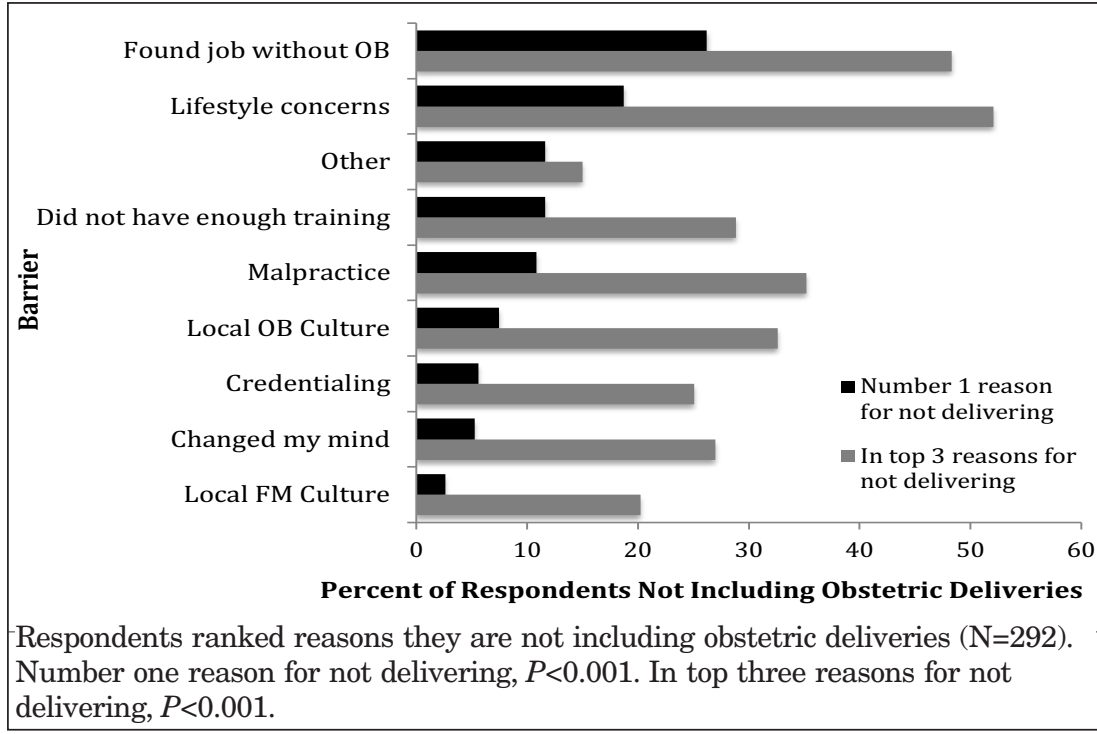

their practice. Less than $50 \%$ of respondents in the Middle Atlantic and West South Central regions included obstetric deliveries, which is particularly striking in the context that all respondents reported intention to include obstetrics in their last year of residency. The ability to find a job that includes obstetrics may vary based on region and rurality. Policy makers and hospital administrators should consider this regional disparity, as offering a broad scope of practice may help attract family physicians to certain locations.

The majority of respondents who included obstetrics in their practice reported less than 40 deliveries per year. While this is not surprising considering obstetrics is often a single piece in the broad scope of family medicine and many are practicing in rural areas, it may lead to potential credentialing concerns if obstetric skills cannot be maintained. Notably, family physicians' delivery volumes do not appear to be associated with adverse maternal or neonatal outcomes. ${ }^{22}$ However, credentialing regulations may not be based on outcomes. For family physicians who stop including obstetrics over time, the low to medium volume of deliveries might play a role in the decision to stop providing obstetric care.
We were encouraged to find that $68.9 \%$ of respondents were currently including obstetric deliveries in their practice. However, the study group was only family physicians who reported intention to include obstetric deliveries, so perhaps $68.9 \%$ should

Despite the almost $50 \%$ response rate, one limitation of this survey study included the possibility of selection bias, in that physicians particularly committed to and interested in obstetric deliveries may have been more likely to complete the survey. Relatedly, it is possible that the number of family physicians who intended to do obstetrics but do not were underrepresented. A second limitation was the short length of the survey, which limits the level of detail and complexity obtained from each respondent. In an effort to increase response rates among physicians, we asked only a few questions.

The results from this short survey point to future research directions to better understand family physicians' position in the maternity care workforce. Future studies should aim to gain a better understanding of the facilitators and barriers to doing obstetrics, and potential interventions to mitigate these barriers, particularly specific lifestyle concerns and be considered low. how physicians are looking for and identifying jobs. Studies assessing employer perspectives and reasons for offering (or not offering) family medicine jobs with obstetrics, including attention to institutional, regional, and state regulatory and cultural differences, would also contribute to a more robust understanding of family medicine's role in providing maternity care in the future.

CORRESPONDING AUTHOR: Address correspondence to Tyler Barreto, MD, Department of Family and Community Medicine, University of Texas Health Science Center, 7703 Floyd Curl Dr MC 7795, San Antonio, TX 78284.765-307-1082. barreto@uthscsa.edu.

\section{References}

1. Coutinho AJ, Cochrane A, Stelter K, Phillips RL Jr, Peterson LE. Comparison of Intended Scope of Practice for Family Medicine Residents With Reported Scope of Practice Among Practicing Family Physicians. JAMA. 2015;314(22):2364-2372

2. Grumbach K. To be or not to be comprehensive. Ann Fam Med. 2015;13(3):204-205.

3. Makaroff LA, Xierali IM, Petterson SM, Shipman SA, Puffer JC, Bazemore AW. Factors influencing family physicians' contribution to the child health care workforce. Ann Fam Med. 2014;12(5):427-431.

4. Barreto TW, Eden AR, Petterson S, Bazemore AW, Peterson LE. Intention Versus Reality: Family Medicine Residency Graduates' Intention to Practice Obstetrics. J Am Board Fam Med. 2017;30(4):405-406.

5. Bazemore A, Petterson S, Peterson LE, Phillips RL Jr. More Comprehensive Care Among Family Physicians is Associated with Lower Costs and Fewer Hospitalizations. Ann Fam Med. 2015;13(3):206-213.

6. Chen FM, Huntington J, Kim S, Phillips WR, Stevens NG. Prepared but not practicing: declining pregnancy care among recent family medicine residency graduates. Fam Med. 2006;38(6):423-426.

7. Barreto T, Peterson LE, Petterson S, Bazemore AW. Family Physicians Practicing High-Volume Obstetric Care Have Recently Dropped by OneHalf. Am Fam Physician. 2017;95(12):762.

8. Rayburn WF. The obstetrician-gynecologist workforce in the United States. Washington, DC: American Congress of Obstetricians and Gynecologists; 2011:119-135, https://www.acog. org/ /media/BB3A7629943642ADA47058D0BDCD1521.pdf. Accessed September 28, 2017.

9. Hung P, Henning-Smith CE, Casey MM, Kozhimannil KB. Access To Obstetric Services In Rural Counties Still Declining, With 9 Percent Losing Services, 2004-14. Health Aff (Millwood). 2017;36(9):1663-1671.

10. Hung P, Kozhimannil KB, Casey MM, Moscovice IS. Why Are Obstetric Units in Rural Hospitals Closing Their Doors? Health Serv Res. 2016;51(4):1546-1560. 
11. Roberts RG, Bobula JA, Wolkomir MS. Why family physicians deliver babies. J Fam Pract. 1998;46(1):34-40.

12. Larimore WL, Sapolsky BS. Maternity care in family medicine: economics and malpractice. J Fam Pract. 1995;40(2):153-160.

13. WWAMI Rural Health Research Center. Rural Urban Commuting Area Codes Data. http:// depts.washington.edu/uwruca/ruca-data.php. Accessed November 30, 2017.

14. US Census Bureau. 2010 geographic terms and concepts - census divisions and census regions. http://www.census.gov/geo/reference/ gtc/gtc_census_divreg.html. Accessed May 5, 2010.

15. The Physicians Foundation/Merritt Hawkins. Survey of America's Physicians: Practice Patterns and Perspectives. 2016.
16. Xu X, Siefert KA, Jacobson PD, Lori JR, Gueorguieva I, Ransom SB. Malpractice burden, rural location, and discontinuation of obstetric care: a study of obstetric providers in Michigan J Rural Health. 2009;25(1):33-42.

17. Smits AK, King VJ, Rdesinski RE, Dodson LG, Saultz JW. Change in Oregon maternity care workforce after malpractice premium subsidy implementation. Health Serv Res. 2009;44(4):1253-1270.

18. Tietze PE, Gaskins SE, McGinnis MJ. Attrition from obstetrical practice among family practice residency graduates. J Fam Pract. 1988;26(2):204-205.

19. Koppula S, Brown JB, Jordan JM. Experiences of family medicine residents in primary care obstetrics training. Fam Med. 2012;44(3):178182.
20. Sutter MB, Ramakrishna, Roberts MB, Magee SR. Teaching maternity care in family medicine residencies: what factors predict graduate continuation of obstetrics? A 2013 CERA program directors study. Fam Med. 2015;47(6):459-465.http://www.stfm.org/FamilyMedicine/Vol47Issue6/Sutter459. Accessed January 14, 2018.

21. Peterson LE, Bo F, Puffer JC, Bazemore A. Wide gap between preparation and practice of early career family physicians. J Am Board Fam Med. 2018; 31(2):181-182.

22. Klein MC, Spence A, Kaczorowski J, Kelly A, Grzybowski S. Does delivery volume of family physicians predict maternal and newborn outcome? CMAJ. 2002;166(10):1257-1263. 